\title{
Small angle neutron scattering study of a gehlenite-based ceramic fabricated from industrial waste
}

\begin{abstract}
This paper presents a small angle neutron scattering (SANS) study of a novel porous gehlenitebased ceramic, synthesised from a homogeneous powder mixture of soda-lime-silicate (SLS) glass, $\alpha$-alumina, calcite and calcium fluoride via solid-state sintering at $1200{ }^{\circ} \mathrm{C}$. The products of sintering at single temperatures from 600 to $1200{ }^{\circ} \mathrm{C}$ are examined by X-ray diffraction (XRD). Sintering of the mixture below $1200{ }^{\circ} \mathrm{C}$ forms two intermediate phases $\left(\mathrm{Na}_{2} \mathrm{CaSi}_{3} \mathrm{O}_{8}\right.$ and $\mathrm{Ca}_{4} \mathrm{Si}_{2} \mathrm{O}_{7} \mathrm{~F}_{2}$ ). Nepheline and $\alpha$-alumina are minor phases in the gehlenite-based ceramic fabricated through sintering at $1200{ }^{\circ} \mathrm{C}$. The microstructure of the gehlenite-based ceramic is investigated using field-emission scanning electron microscopy (FESEM) and SANS at the Australian Centre for Neutron Scattering. This study also evaluated the specific surface area of the gehlenite-based ceramic $\left(\sim 3.0 \mathrm{~m}^{2} \mathrm{~cm}^{-3}\right)$ from quantitative analysis of SANS data.
\end{abstract}

Keyword: Neutron scattering; Gehlenite; Ceramic; Waste; Solid-state sintering 